\title{
A STUDY ON THE DOCUMENT INFORMATION SERVICE OF THE NATIONAL AGRICULTURAL LIBRARY FOR AGRICULTURAL SCI-TECH INNOVATION IN CHINA
}

\author{
Qian $\mathrm{Xu}^{*}$, Xianxue Meng \\ Agricultural Information Institute of Chinese Academy of Agricultural Sciences, Beijing, \\ P. R. China 100081 \\ * Corresponding author, Address: Agricultural Information Institute of Chinese Academy of \\ Agricultural Sciences, Beijing 100081, P. R. China, Tel: +86-13488769681, Email: \\ xuqian.19840115@163.com
}

\begin{abstract}
This paper presents the significant function of the Chinese National Agricultural Library (CNAL) in the agricultural sci-tech innovation system in China, analyses the development of collection and service in the CNAL, explores the challenge towards sustain and develop information services for the agricultural sci-tech research and innovation, at last proposes the strategy for sci-tech document information service development.
\end{abstract}

Key words: document information service, sci-tech innovation, Chinese National Agricultural Library (CNAL)

\section{INTRODUCTION}

Along with the speed of science and technology increased, sci-tech document information resources have become a necessary and stable basis for the further development of science and technology, and also have become the national strategic resources all over the world. The possessive level of sci-tech document information resources and the efficiency of the information services have become important indicators of a country's

Please use the following format when citing this chapter:

Xu, Q. and Meng, X., 2009, in IFIP International Federation for Information Processing, Volume 295, Computer and Computing Technologies in Agriculture II, Volume 3, eds. D. Li, Z. Chunjiang, (Boston: Springer), pp. 1889-1897. 
science and technology advancement and the social development level. Scitech document information resources construction and utilization have been strongly stressed by all developed countries to support and ensure their scitech leading status in the world.

Up to now, there is a large gap between the agricultural technology level and technology innovation capacity in China and the other developed countries. Therefore, China established the Agricultural Sci-tech Innovation System, aiming to promote agricultural knowledge innovation and agricultural technology innovation. Agricultural sci-tech document information resources construction and service have become necessary supporting conditions for agricultural sci-tech innovation, and an essential part of the Agricultural Sci-tech Innovation System.

The Chinese National Agricultural Library (CNAL), initiated in the 1950s by Agricultural Information Institute ( AII ) of Chinese Academy of Agricultural Sciences (CAAS) to provide document information services for researchers, policy-makers of agricultural research institutes or colleges across the country. Over fifty years, now it has boasted of a unique collection system characterized by document information resources in agriculture and relevant disciplines. The CNAL is the agricultural sciences central library of the National Science and Technology Library (NSTL), which is established in 2000 by the Ministry of Science and Technology, and composed of 7 special libraries from basic sciences, agricultural sciences, medical sciences, and engineering, to form a national reserve library and a supply center for scientific information. Up to now, the CNAL has become the largest agricultural library in Asia, and one of three agricultural libraries in the world.

The main function of the CNAL is to collect, process, storage and delivery Chinese and foreign agricultural sci-tech document information, and to establish an integrated digital scientific information service environment for its users. As the most important agricultural sci-tech document information provision and service system in China, the CNAL plays an important role of supporting national agricultural sci-tech innovation.

Challenges to sustain and develop the CNAL information services lie in three aspects. The first one is the change of science research environment; the second one is the change of operational mechanism of scientific research; the third one is the new needs and information behavior of users in e-science environment.

The objective of this study is to develop the information service strategy for the Chinese National Agricultural Library to improve the quality and capacity of information service for supporting the sci-tech innovation in China. 


\section{DEVELOPMENT OF DOCUMENT INFORMATION SERVICES}

The CNAL integrates the catalog of its physical collection, electronic resources, and special subject research information developed by CNAL or AII into the platform of National Agricultural Information System (NAIS), and provides its information services via this platform. The platform of NAIS is showed in Fig.1.

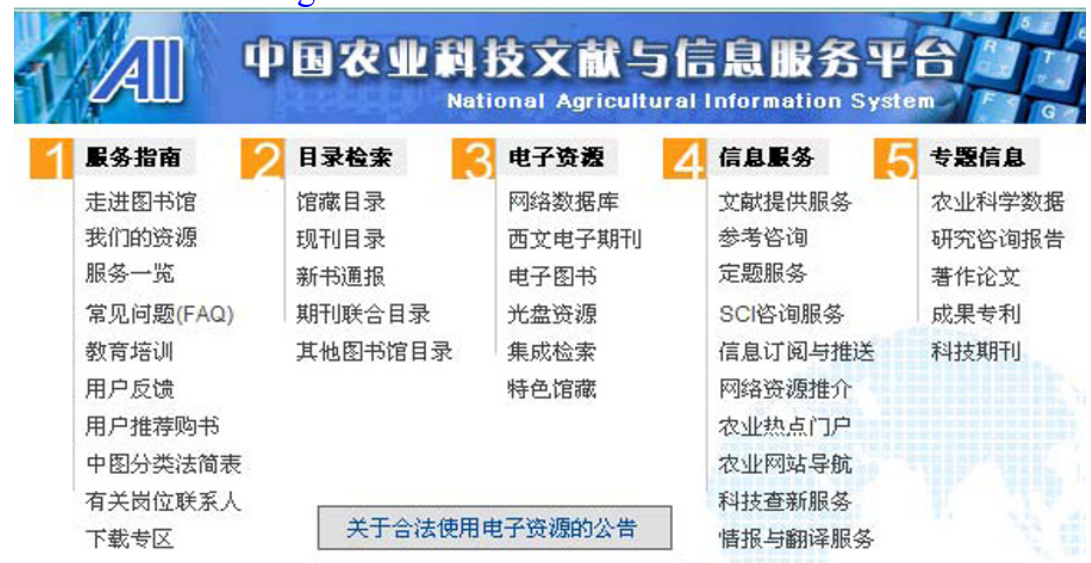

Fig. 1: The platform of National Agricultural Information System

The information service in CNAL can be classified in two types. They are traditional lending service, and network-based information services. As showed in Fig.1, the main functions of information service are listed in the platform of NAIS. The feature of the information services of CNAL can be characterized in two aspects: the resource integration and the service integration.

\subsection{The integration of document information resources}

The document information resource is the necessary basis for information services. First, document information resources within the library are integrated according to its type via the columns of Catalog Searching, Electronic Resource and Special Subject Research Information in the platform of NAIS. Second, different types of electronic resources are also integrated in the platform, which provides users the convenient services of browsing-online, resource retrieval and documents supply. The integrated retrieval system provides a uniform retrieval platform among different plats databases. In addition, the NAIS realizes the integration of collection within the library and network resources out of the library via the columns of Union 
Catalog Searching, Agriculture Website Navigation, Network Resources Recommendation and Link, and Portals for Agricultural Resources, et al.

The information resources integration mentioned above is still an organization of documents and data information at an early stage, and is not able to provide an adequate support for researchers or scientists to filter through mass-scale content to explore unknown knowledge. The real meaning of resource integration is an in-depth integration of document content distributed in different types of resource, constructing the relationship among content points in one database or among different databases.

\subsection{The integration of services}

In terms of the function of service, the platform of NAIS provides integrated one-stop information services. It developed the interlibrary loan service to delivery required articles to user's e-mail box. Opened digital reference service to enable users to receive librarians' help via the internet and provided training sessions for individual agricultural research institutes within and outside CAAS.

In addition, agriculture resources navigation service introduces and offers important sci-tech websites from all over the world, including that of important agricultural scientific and technology institutions and information institutions, aiming at guiding the users' choosing their useful resources.

What's more, the platform provides the users who register the Green Channel service with authentication and authorization services which enable the users to request NAIS's services no matter where they are.

\section{CHALLENGES TO SUSTAIN AND DEVELOP DOCUMENT INFORMATION SERVICES}

\subsection{Changes of the scientific research environment}

Scientific research environment is or will be a ubiquitous digital environment, which can be summarized in two aspects. First, not only the formal scholar information sources, such as journals, books, technical reports, conference papers, theses and dissertations, patents, etc., are almost totally digitally accessible, but an ever increasing volume of informal information published as research results by individuals or institutions is also available online (Kayvan and Mike, 2008). The digital information environment and the quick and easy access it provides to vast amounts of digital information from a wide range of sources have greatly affected the 
way in which users seek information and make use of the resource. Secondly, it becomes a normal way for most scientists to depend upon internet tools, such like e-mail, web-site, discussion forums, and file transfer, to communicate with each other, conduct information exchange.

In addition, the environment of scientific and scholar information communications is also undergoing a dramatic change. Access to information is no longer inter-mediated by and channeled through a library when forces like Google Scholar/Print, open access materials, and institutional repositories are creating a new information supply chain. Publishers, database producers, commercial search engine producers, citation index service providers and other content brokers are all going into the information service market, not only providing information services more directly and effectively to users by an open or commercial system, but also becoming increasingly active in knowledge-oriented and high addedvalue services such as personalized services, and reference services. This calls for a new definition of information resources, information organization, and information service integration (Zhang Xiaolin, 2005).

\subsection{Science is increasingly operating in a digital fashion}

The operational mechanisms of scientific research is even increasingly become digital. E-science or cyber-infrastructure creates a networked infrastructure rich in data grids, computing grids, digital libraries, and collaboration. All kinds of scientific objects, including people, programs, facilities, data and documents, procedures and workflows, and even policies and strategies, can be and will be digitally represented, accessed, interconnected, and invoked through networked interaction. Scientists are able to share observation and experiment resources, share data and information recourses, share computing and analysis capabilities cross time, space, and administrative boundaries (Zhang Xiaolin, 2005). Information becomes the target of research analysis and processing for data mining and knowledge discovery. Networked collaboration, multi-system cooperation, and process management of virtual research organization constitute the basic supporting mechanism for large research undertakings.

\subsection{Changes of users' information needs}

Due to the ubiquitous digital information environment, the bottleneck of the users' information activities has shifted from document-based information retrieval to relationship-based knowledge discovery. Traditional library service usually covers collecting, processing, retrieval and delivery of information resources, with less analyzing the inter-relationship of the 
content or the concepts. It can not be an adequate support to scientists' core missions. Effective services are required to help users to mine knowledge and knowledge relations among mass of various scientific objects. The information activities and information services should also diffuse into and interact with the totality of users' problem-solving processes and users' information environment.

\section{STRATEGIES FOR DEVELOPING THE DOCUMENT INFORMATION SERVICE}

The CNAL will take those challenges as an opportunity to develop its document information services for a better support to agricultural sci-tech innovation in China. In this part, some strategies for improving information services are proposed.

\subsection{In-depth integration of the service resources}

Central to scientific research, users put high value on the systematization and specialization of information or knowledge. Information resource integration not only requires a systematic collaborative system consisting of printed collections, electronic information databases, and third-party resources, but also expects to re-organize those information objects and construct a systematic knowledge organization for the further creation of knowledge by conducting knowledge mining, which reveals the hidden relationship between concepts. What is more, based on the knowledge-based organization, inter-related information or knowledge resources concerned with one study or a special subject could be put together into a desired pattern and structure. They can be organized into horizontal information networks in different study fields, or linked together to form vertical information chains according to demands of the users.

In addition, facing with the increasingly urgent needs for varied information resource, together with the situation of the decentralized distribution of documents, CNAL should pay more attention to the sic-tech information resource sharing with diversities libraries and agricultural scitech document information service institutions in China by establishing an information resources processing and service system on the basis of digitalizing technology and networking technology. This is not only meaningful for the actually better exploit and utilizing the current agricultural sci-tech document information resources, but also brings significant impacts on the communication and collaboration between Chinese and international information network systems. 


\subsection{Enhancing the information analysis service}

Information analysis mentioned goes beyond regular catalog compilation or literature review, but knowledge mining, knowledge discovery and knowledge organization concentrating on problem-solving, which supports strategy planning, discipline trend analysis, sci-tech policy analysis, research evaluation, and deals more with unknown or potential problems, with concept and relationship analysis, and knowledge creation. Information analysis not only supports the current sci-tech research, but also could stimulate new research. Therefore, information analysis enables the library the better service for decision-making and scientific research.

To strengthen the capacity of information analysis, on one hand, CNAL needs to develop technical tools, network-based collaboration platform to identify meaningful, unknown relationships between concepts, enable broader inquiry of the scientific literature (Bernard and Jeffrey, 2006), and depict content points and relationship hiding behind. On the other hand, while knowledge discovery techniques can uncover hidden relationships in the data and documents, it depends on the user's expertise to give those relationships meaning (Bernard and Jeffrey, 2006). Therefore, knowledge discovery techniques should be designed into the scholar process for discipline analysis, opportunity discovery, development evaluation, trend forecast, strategy planning, and should be integrated into user's own information system for the sake of the personalized needs.

\subsection{Developing the knowledge service mechanism}

The core mission of information service in the current situation is to support users' information needs and resolve their problem directly and effectively. Since the collection-oriented workflows and library-centered service are not adequate, the new user-centered and problem-solvingoriented service mechanism of library is called upon, and services diffusing into and interacting with users' research processes are essential for success in such a situation.

Traditional libraries often center their information services on the "circulation of collections", and put themselves out of the research workflow, leading to a less active enrollment of the librarians to the science environment, whose ability to follow research needs closely and sufficiently is severely limited.

Aiming to develop user-centered digital library services, which diffuse into research environment, collaborative mechanisms should be introduced to libraries for librarians to work together with researchers in terms of knowledge process and to provide further personalized services. 
To sum up, user-centered service is the active and interactive personalized service. It is conducted by libraries in accordance with users' needs in their research process, with the aim of helping users to resolve their problem and accomplish the research task. This service patter poses emphasize on forming a partnership with researchers, and operating closely into and together with research or knowledge process.

\subsection{Adopting CRM to enhance the study on user's information needs}

Customer relationship management (CRM), evolving from business processes, emphasizes not only a comprehensive strategy, but also a process of acquiring, retaining and partnering with selective customers to create superior value for the company and the customer (Parvatiyar and Sheth, 2000).

The concept of CRM aims at facilitating the realization for more effective customer personalization management. Although more and more organizations and companies have "begun to use the Internet to obtain customer information in their database marketing processes to enhance customer relationship management" (O'Leary et al., 2004), few libraries have employed sophisticated CRM information systems. When it comes to digital library, CRM could be interpreted as a method of management on customer information, which is an important resource for libraries. Taking advantage of deep analysis on the customer information, libraries could have a better know about the clients' information needs and behavior. Accordingly, it could improve their information services. Central to the conception of developing customer relationships, libraries put high value on the discovery of potential customers, and also on developing potential users to real ones, so as to keep the expansion of the scope of information service.

Therefore, the CNAL could think about adopting more CRM concept and applications as one of the possible solutions to secure users' satisfaction while facing the challenges brought by proliferated information service channels, information explosion, and users' higher expectations.

\section{CONCLUSION}

As the most important agricultural sic-tech document information provision and service system in China, the National Agricultural Library plays an increasingly important role in supporting national agricultural scitech innovation system. Facing with the limitation of development and the challenges proposed by environment outside, strategies for developing the document information service are proposed in terms of the service resource 
development, the service content, the service mechanism and the service management.

There are still various factors or aspects needed to be considered and studied to develop a systematic strategy for improving the document information service in CNAL with regarding to serving the sci-tech innovation. But what important is the vision and the approaches for CNAL development. It is the author's believe that the viability and sustainability of CNAL lie in its in-depth integration of document information services and in its supporting for the scientific decision-making. The strategies outlined are the experimental steps toward this goal.

\section{REFERENCES}

A. Parvatiyar, J. N. Sheth. The domain and conceptual foundations of relationship marketing, in J. N. Sheth, A. Parvatiyar (Eds), Handbook of Relationship Marketing, Sage Publications, Thousand Oaks, CA, 2000: 3-38

C. O'Leary, S. Rao, C. Perry. Improving customer relationship management through database/internet marketing: a theory-building action research project, European Journal of Marketing, 2004, 38(3/4): 338-354

D. Bernard, D. Jeffrey. Knowledge Discovery in the Digital Library: access tools for mining science, Information Services and Use, 2006, 26(1): 39-44

http://www.ifla.org/IV/ifla71/Programme.htm

K. Kayvan, T. Mike. Sources of Google Scholar Citations outside the Science Citation Index: A comparison between four science disciplines, Scientometrics, 2008, 74(2): 273-294

Zhang Xiaolin. From Digital Library to E-Knowledge Development Strategy, Journal of Library Science in China, 2005, 31(158): 273-294(in Chinese)

Zhang Xiaolin. Sustainable Digital Library Development for Scientific Communities. In The Proceedings of World Library and Information Congress: 71th IFLA General Conference and Council, August 14th - 18th, 2005, Oslo, Norway. 